\title{
Awareness and Practice of Oral Hygiene Measures amongst College Students of Lahore
}

\author{
MUHAMMAD SHAIRAZ SADIQ ${ }^{1}$, ZAID BIN SOHAIL ${ }^{2}$, FARHAN RIAZ ${ }^{3}$, MUHAMMAD SALMAN CHISHTY ${ }^{4}$, \\ MEHWISH MUNAWAR ${ }^{5}$, SAIMA SABIR ${ }^{6}$ \\ ${ }^{1}$ Associate Professor Oral Medicine CMH Lahore Medical College \& Institute of Dentistry \\ ${ }^{2}$ Demonstraror Oral medicine CMH Lahore Medical College \& Institute of Dentistry \\ ${ }^{3}$ Assistant Professor Community Dentistry Faryal Dental College \\ ${ }^{4}$ Assistant Professor Oral \& Maxillofacial Surgery CMH Lahore Medical College \& Institute of Dentistry \\ ${ }^{5}$ Assistant Professor Operative Dentistry University College of Dentistry, University of Lahore \\ ${ }^{6}$ BDS, M.Phil Physiology Senior Demonstrator Islam Dental College, Sialkot \\ Correspondence to: Dr. Muhammad Shairaz Sadiq, Email: dr_shairaz@hotmail.com, Cell: +92 3334364364
}

\begin{abstract}
Objective: To evaluate awareness and practice of oral hygiene measures amongst college students of Lahore. To assess awareness and practice of oral hygiene measures amongst students of CMH LMC, LUMS, UET, FAST, Punjab College \& Lahore Garrison University

Materials and Methods: A survey was conducted among non-dental students using a questionnaire.

Results: Most frequently used oral hygiene measure was toothbrush (81.3\%). Most frequently used interdental aid was toothpick. (53.8\%). $68 \%$ of the participants were aware about oral hygiene and most common mode of awareness was by dental fraternity $34.6 \%$. $51 \%$ of the participants were using interdental aids. $49 \%$ of the participants were not using oral hygiene adjuncts and the most common reason was not knowing how to use it. $(28.8 \%)$

Conclusions:68\% of the participants were aware about oralhygiene measures but only half of the participants in this study engaged in regular oral hygiene measures and lack of knowledge was the dominant reason for not doing so.
\end{abstract}

Key words: oral health, periodontal disease, interdental areas, interdental cleansing,interdental aids.

\section{INTRODUCTION}

Oral health is an essential component of general health can be defined as "a standard of health of oral and related tissues which enable an individual to eat, speak and socialize without active disease, discomfort or embarrassment and which contributes to general wellbeing." 1 Periodontal disease and dental caries are the two most common oral diseases affecting mankind since the dawn of civilization. ${ }^{2}$ Periodontal disease is defined as an inflammatory condition that occurs when there is an imbalance in the interplay between local infection and the inflammatory response of the host.The primary etiological factor implicated in the pathogenesis of periodontal diseases is Plaque. Self-cleaning of the teeth still remains the most effective means of bacteria plaque removal. ${ }^{3,4}$ Self-cleaning of the teeth through mechanical means, leaves the dental surfaces free of any plaque.

Incorporation of the appropriate skills of tooth cleaning should include all the teeth surfaces with emphasis on interdental areas. ${ }^{5}$ similarly, the interdental surfaces are the most implicated locations for the development of periodontal diseases and dental caries. ${ }^{6}$

Many people try to clean the teeth atleast once a day but do only the buccal surface and proper oral hygiene is not optimized by only doing this due to lack of awareness and practice of this.

The most commonly used nonprofessional means of bacteria plaque control is toothbrush. Additional conscious and regular cleaning with interdental cleaning aids is required as toothbrush may leave the interdental areas incompletely cleaned of bacteria ${ }^{6,7}$ Dental floss, interdental wood sticks and interdental brushes are the commonly used interdental cleaning aids. The morphology of the interproximal tooth surface, the size and shape of the interdental area as well as patient factor affects the use of any of these aids in maintaining oral hygiene. ${ }^{7}$ Recent studies have shown that plaque accumulation and gingivitis can be reduced by the interdental cleaning of teeth with the appropriate aids. ${ }^{7,8}$ Most of the people clean all other tooth surfaces and leave the interdental areas untouched as the task is tedious, require meticulousness, as well as good manual skills, so most people tend to neglect this important habit. ${ }^{9}$ It is not known if this is the case in our environment, as there is a dearth of information on interdental cleaning. This becomes more important from a preventive dentistry aspect in this environment as there is poor awareness of basic oral hygiene measures as well as high prevalence of periodontal diseases. ${ }^{10,11,12}$

Many studies have shown oral health behavior of dental students but very little attention has been given to awareness and practice of oral hygiene measures among collegestudents. The attitude and behavior of students toward their oral health care reflect their understanding of the importance of dental procedures. The objectives of this study, therefore, included determining the awareness and practice of oral hygiene measures among the college and university students, determining the aids that are used for this and documenting reasons why they do not engage in this good oral health behavior.

\section{MATERIALS AND METHODS:}

This study was an anonymous, questionnaire-based survey CMH LMC, LUMS, UET, FAST, Punjab college \& Lahore Garrison University. A self-made, pre-tested questionnaire was used which was contain the questions which were close ended. A self-developed, pre- validated close-ended 
questionnaire was used. The population of the current study containsthe students before to collection of data, in a group of 20 students the question were pre- checked (pilot study) to check the degree of repeatability and level of validity. Before filling the questionnaire respondents were informed briefly about study nature and all the procedure of filling questionnaire. The questionnaire was completed anonymously by consenting participants. Ethical committee gave the ethical clearance. On the day of the survey not any attempt was taken for follow up with those students who were absent in the class. Certain operational terms were defined like plaque, calculus and interdental aids for the purpose of the study. Questionnaire contained questions about age and gender as well as questions regarding student's oral hygiene practice, knowledge about interdental aids, its practice and reasons for not practicing inter dental aids.

The students were asked to give response on questionnaire as the format and instructions are given on the questionnaire. The students were encouraged to clear any confusion regarding questions from the investigator for their clarification. Students were asked to fill the questionnaire without the discussion with each other.

The collected data were subjected for statistical analysis using SPSS version 23. Descriptive statistics were obtained and mean percentage scores, standard deviation, and frequency distribution were calculated.

\section{RESULTS}

Total 410 patients participated. Out of which 176 were male (43.1\%) and 234 (56.9\%) werefemale. The results shown in graphs and charts depicts about the very less awareness and practice of oral hygiene measures with different adjuncts and tooth brushing being the only most commonly method to achieve oral hygiene

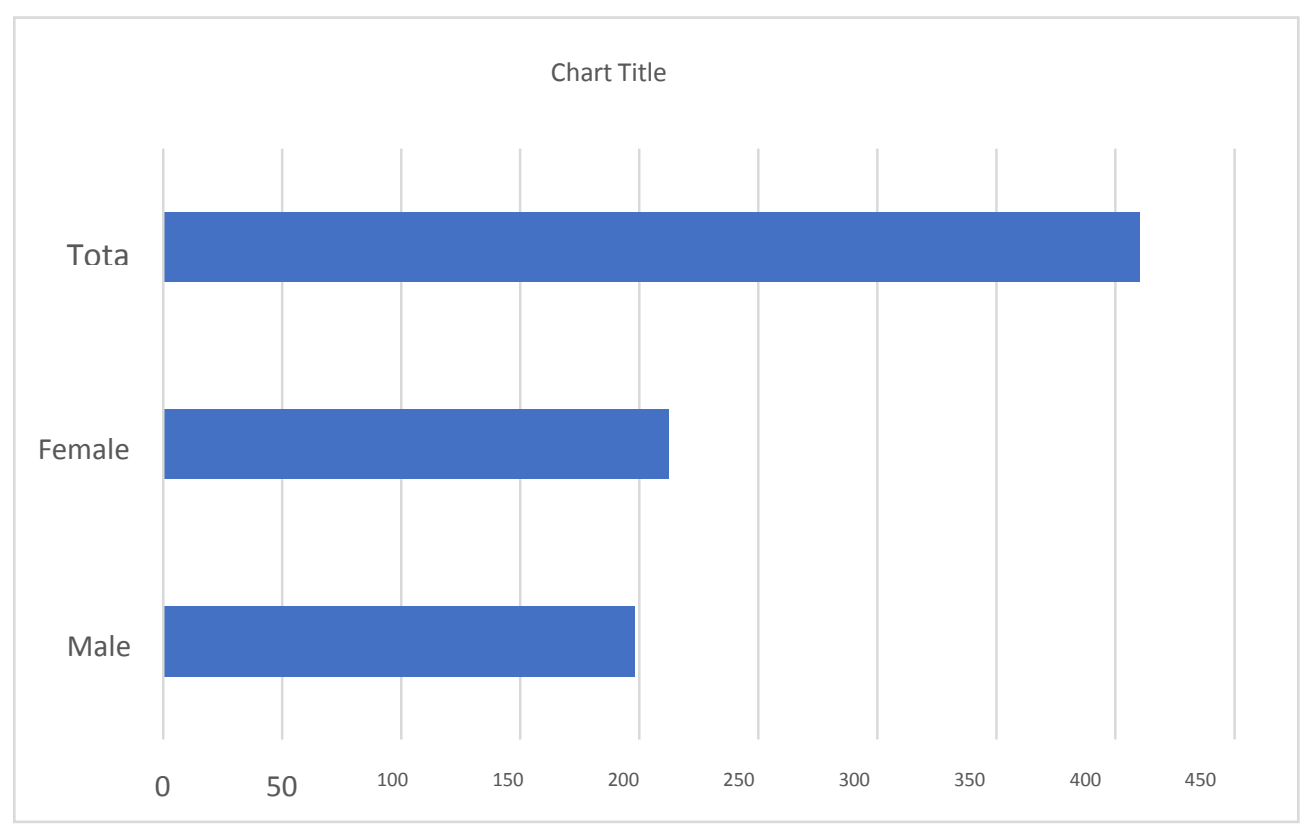

Figure1: Gender distribution of the respondents

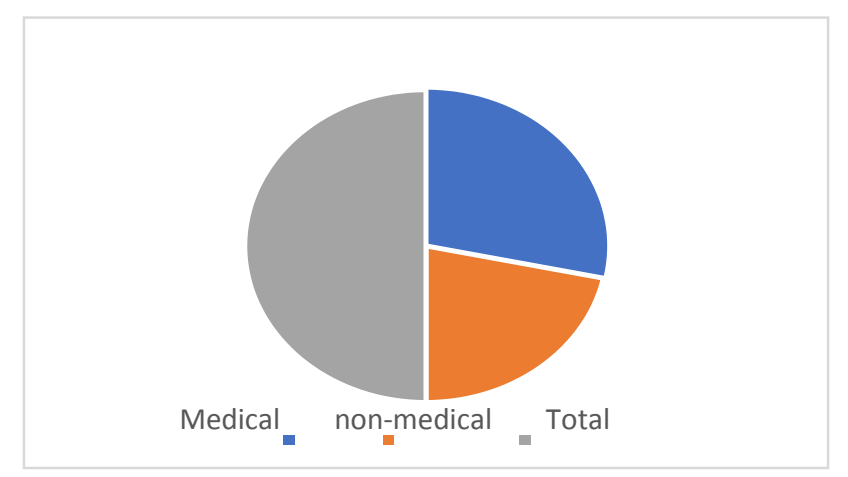

Figure 2: Distribution of Medical and non-medical of the respondents 


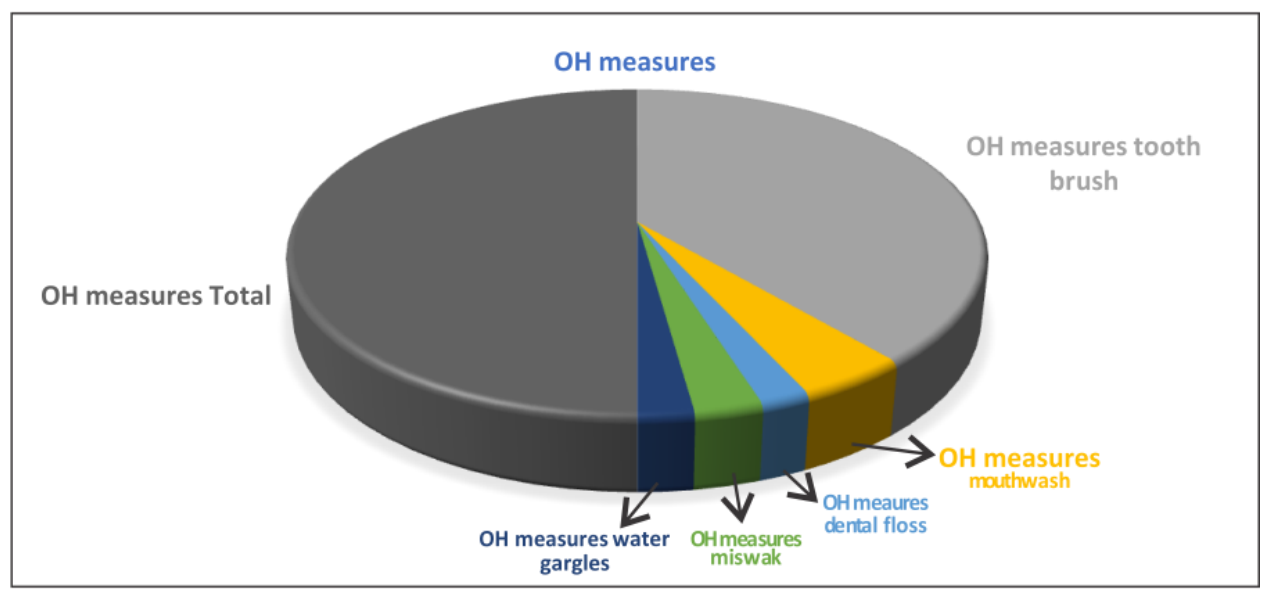

Figeure3: "Distribution of cleaning agent of the respondents"

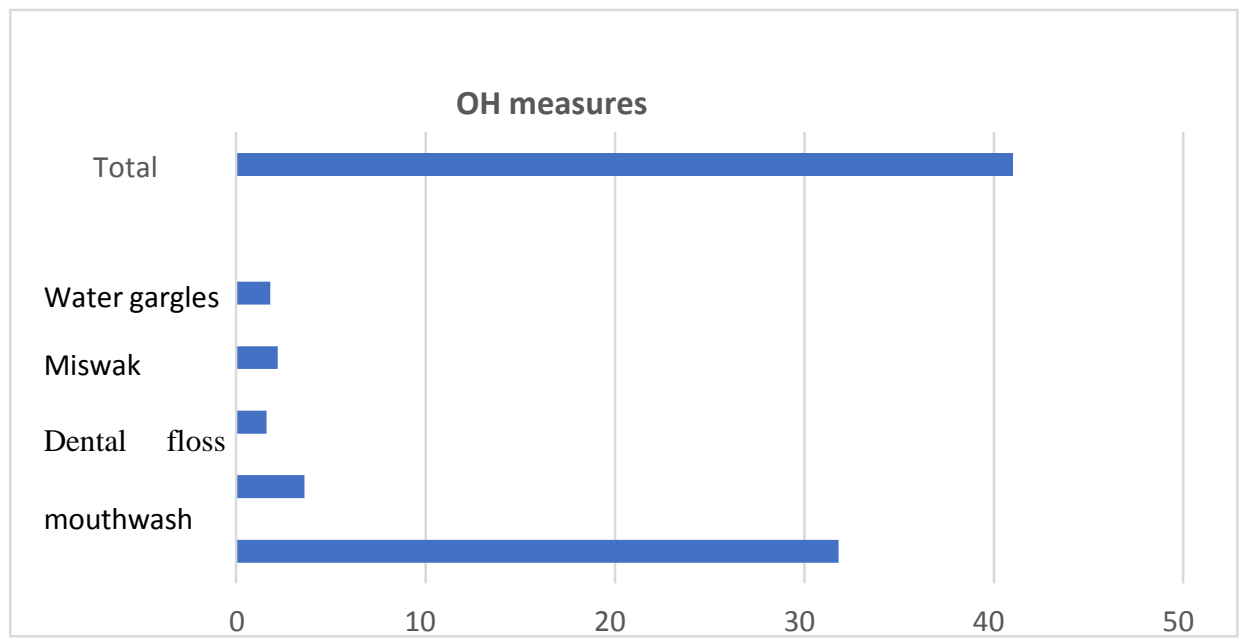

Figure 4:"Distribution wise frequency of cleaning agents"

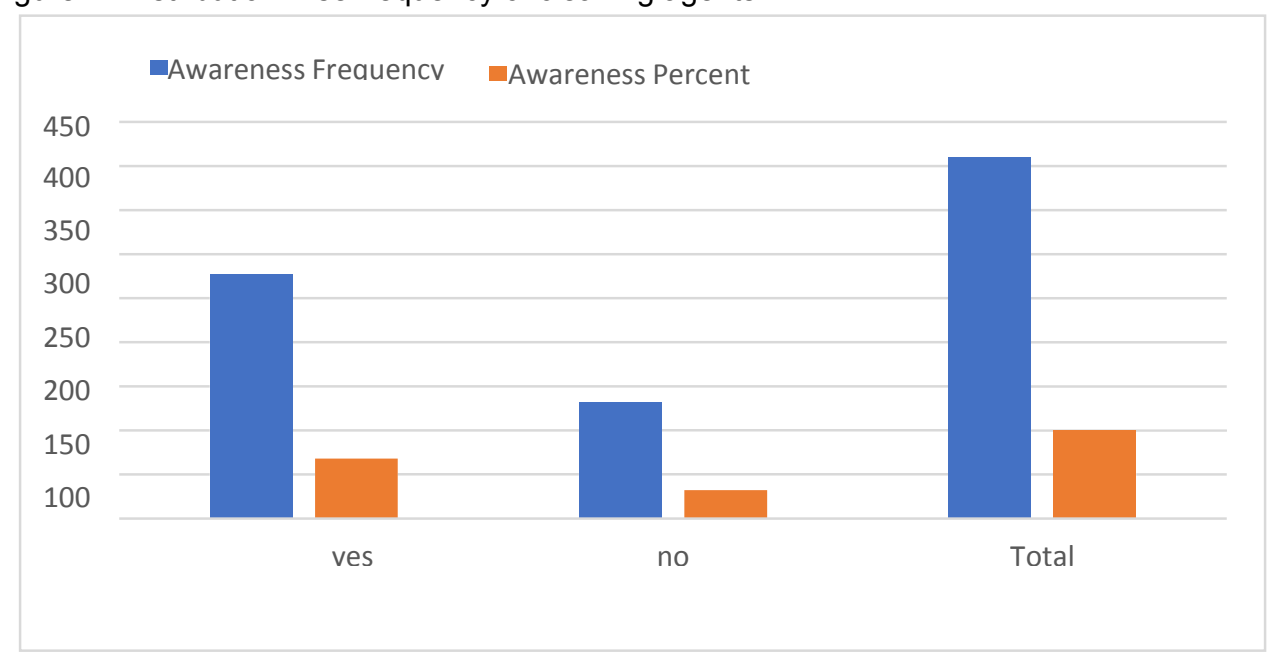

Figure5: Overall frequency of awareness among respondents

\section{DISCUSSION}

Periodontal diseases are prevailing extensively all around the globe. Though this chronic disease is preventable but still notable populations are affected by this. ${ }^{13}$ For a better oral health care, dental students should promote and educate about public dental health. ${ }^{14,15,16} \mathrm{Agood}$ oral health is considered important and pivotal component of good general health. ${ }^{16}$ Biofilm or dental plaque, that is formed, is 
major cause for periodontal diseases and carious lesions at the proximal side hence the bacterial plaque should be disrupted and removed for its prevention. ${ }^{17}$ in our study, tooth brushing was the most commonly method to attain oral hygiene although Toothbrush alone cannot serve for this purpose, therefore for effective removal of dental plaque other oral hygiene aids such as dental floss should be adjuvant to it. ${ }^{18}$ Dental floss is considered more effective for removal of plaque. ${ }^{19}$ It has been reported that daily use of dental floss not only prevents periodontal disease but also reduces the risk of cardiovascular disease. ${ }^{20}$ but in our study,most of the students were not aware about the dental floss and other oral hygiene adjuncts neither they were advised routinely in thedental practice. ${ }^{21}$

\section{CONCLUSION}

$2 / 3$ of the participants were aware about oral hygiene measures but less than half of the participants in this study were actually doing some sort of oral hygiene measures and lack of knowledge was the dominant reason for not practicing it.

\section{REFERENCES}

1. Carneiro L, Kabulwa M, Makyao M, Mrosso G, Choum R. Oral health knowledge and practices of secondary school students, tanga, Tanzania. Int J Dent 2011. 2011806258.

2. Vaish S, Ahuja S, Dodwad V. A comparative evaluation of oral hygiene practices and periodontal status among dental and paramedical students: An epidemiological survey. Journal of Indian Dental Association. 2010;4:343-346.

3. Westfelt E. Rationale of mechanical plaque control. J ClinPeriodontol 1996;23:263-7

4. Negrato CA, Tarzia O, Jovanovic L, Chinellato LE. Periodontal disease and diabetes mellitus. J Appl Oral Sci 2013;21:1-12.

5. Kocher $T$, Sawaf $H$, Warncke M, Welk A. Resolution of interdental inflammation with 2 different modes of plaque control. J ClinPeriodontol 2000;27:883-8

6. Claydon NC. Current concepts in toothbrushing and interdental cleaning. Periodontol 20002008;48:10-22.

7. Berchier CE, Slot DE, Haps S, Van der Weijden GA. The efficacy of dental floss in addition to a toothbrush on plaque and parameters of gingival inflammation: A systematic review. IntJ Dent Hyg 2008;6:265-79.

8. Crocombe LA, Brennan DS, Slade GD, Loc DO. Is self interdental cleaning associated with dental plaque levels, dental calculus, gingivitis and periodontal disease? J Periodontal Res 2012;47:188-97

9. Wolff A, Staehle HJ. Improving the mechanical properties of multiuse dental floss holders. Int J Dent Hyg 2014;12:245-50.

10. Taiwo JO, Jeboda SO, Motayo TO, Obiechina AE. Periodontal health of the elderly people in South East local government area in Ibadan, Nigeria. Afr $\mathrm{J}$ Med MedSci 2004;33:285-91

11. Umoh A, Azodo C. Association between periodontal status, Oral hygiene status and tooth wear among adult male population in Benin City, Nigeria. Ann Med Health Sci Res 2013;3:149-54

12. Adeyemi BF, Kolude BM, Lawal AO. The knowledge and experience of personal and professional oral care among secondary school students in Ibadan. Odontostomatol Trop 2012;35:5-11.

13. Jin LJ,ArmitageGC,Klinge B, Lang NP,Tonetti M, Williams RC. Global oral health inequalities: Task group-periodontal disease. Adv Dent Res 2011;23:221-6.

14. KhamiMR, Virtanen JI, Jafarian M, Murtomaa H. Preventionoriented practice of Iraniansenior dental students. Eur J Dent Educ 2007;11:48-53.

15. Gallagher EB,Moody PM. Dentists and the oral health behaviorof patients: A sociologicalperspective. J Behav Med 1981;4:283-95.

16. Frazier PJ. Public health education and promotion for caries prevention: The role ofdental schools. J Publec Health Dent 1983;43:28-42.

17. Carneiro L ,Kabulwa M, Makyao M, Mrosso G, Choum R Oral health knowledge and practices of secondary school students, Tanga, Tanzania. Int J Dent 2011;2011:806258.

18. Pinto TM, de freitasGC,DutraDA,KantorskiKZ,Moreira $\mathrm{CH}$. Frequency of mechanical removal of plaque as it relates to gingival inflammation: A randomized clinical trial. J Chin Periodontal 2013;40:984-54.

19. Gluch JI. As an adjuvant to tooth brushing and interdental brushes (IDBs) are more effective in removing plaque as compared with brushing with brushing alone or the combination use of tooth brushing and dental floss. J Evid Based Dent Pract 2012;12:81-3.

20. Bellamy P,Barlow A, Puri G, Wright KI, Mussett A, Zhou X. A new in vivo interdental sampling method comparing a daily flossing regime versus a manual brush control. J Clin Dent 2004;15:59-65

21. El Fadi KA, Ragy N, El Batran M, Kassem N, Nasry SA, Khalifa R, et al. Periodontitis and cardiovascular disease: Floss and reduce a potential risk factor for CVD. Angiology 2011;62:62-7. 